\title{
Multispectral satellite mapping of crop residue cover and tillage intensity in lowa
}

\author{
P.C. Beeson, C.S.T. Daughtry, E.R. Hunt Jr., B. Akhmedov, A.M. Sadeghi, D.L. Karlen, and M.D. Tomer
}

\begin{abstract}
Quantifying crop residue cover is crucial for identifying tillage intensity and evaluating effectiveness of conservation management practices across large geographic areas. Current assessment protocols are labor intensive, time consuming, and costly. Our objective was to assess crop residue cover and soil tillage intensity in a watershed in central Iowa for three years (2009 to 2011) using multispectral satellite images. The watershed is dominated by corn (Zea mays L.) and soybean (Glycine max [L.] Merr.), which are grown on glacial-till derived soils across $85 \%$ of the land area. For each year, crop residue cover was measured for a few fields using the line-point transect method or visually estimating surface cover through roadside surveys. Conservation tillage fields had $\geq 30 \%$ residue cover, while more intensively tilled fields had $<30 \%$ residue cover. Landsat Thematic Mapper (TM), Système Pour l'Observation de la Terre (SPOT) High Resolution Geometrical (HRG), Indian ResourceSat Advanced Wide Field Sensor (AWiFS), and Deimos satellite images were also acquired and analyzed to determine surface cover. SPOT and Landsat images provided similar classification accuracy ranging from $64 \%$ to $92 \%$, while AWiFS and Deimos classifications had accuracies ranging from $61 \%$ to $73 \%$. Clouds and the revisit interval for each satellite affected the timing of satellite images with respect to field operations, which also influenced classification accuracy. Overall soil tillage intensity varied little from year-to-year. Soil tillage intensity was also mapped as a function of slope, which could be useful for targeting additional conservation practices throughout the watershed. We conclude that satellite imagery is well suited for classifying crop residue cover. Furthermore, two recently launched satellites, Landsat- 8 and Sentinel-2, have comparable multispectral sensors and together these satellites should provide frequent opportunities to acquire suitable imagery for assessing crop residue cover and soil tillage intensity over large geographic areas.
\end{abstract}

Key words: conservation agriculture — conservation tillage-maize-remote sensing

\begin{abstract}
Soil tillage intensity can be characterized by the proportion of the soil surface covered by crop residue shortly after planting, with $\langle 15 \%$ residue cover classified as intensive or conventional tillage, $15 \%$ to $30 \%$ residue cover as reduced tillage, and $130 \%$ residue cover as conservation tillage (CTIC 2009). Accurate assessments of crop residue cover are important for evaluating effectiveness of conservation practices because of the numerous ecosystem services (e.g., decreased soil erosion, increased soil organic matter, improved soil and water quality, and reduced carbon dioxide $\left[\mathrm{CO}_{2}\right]$ emissions) that crop residues on the soil surface influence (Daughtry et al. 2012; Lal et al. 2004).

Accurate estimates of crop residue cover are also important for modeling water qual-
\end{abstract}

used to create decades-long crop sequences for multiple fields within watersheds or other regions of interest (Beeson et al. 2011). However, soil tillage intensity, an important parameter for many agroecosystem models, is difficult information to obtain because, to our knowledge, there is no organized program for objectively collecting this information on a field by field basis across large regions. The Conservation Technology Information Center (CTIC) compiles annual assessments of soil tillage intensity for a limited number of counties in the United States. These roadside surveys are costly, subjective, and the techniques used vary from county to county (Thoma et al. 2004). While these summaries provide useful information on the average tillage intensity for a county, they do not provide the specific geospatial information needed to improve the spatial resolution of agroecosystem models and verify the effectiveness of crop and soil management strategies.

The standard technique used by USDA Natural Resources Conservation Service (NRCS) is the line-point transect where a 15 to $30 \mathrm{~m}$ (49.2 to $98.4 \mathrm{ft}$ ) line with 100 evenly spaced markers along the line is stretched diagonally across the crop rows in the field and markers intersecting crop residue are counted (Morison et al. 1993). Although the line-point transect method is robust for assessing crop residue cover in a single field, it is impractical for monitoring crop residue cover in many fields over broad areas in a timely manner.

Remote sensing may provide an efficient, timely, and objective method of obtaining information on soil tillage intensity over large areas. However, soils and crop residues are spectrally similar and often differ only in amplitude in the relatively broad spectral bands of most multispectral sensors (Serbin models have been developed for evaluating nutrient losses and $\mathrm{C}$ sequestration associated with various crop and soil management scenarios including adoption of conservation practices (Abrahamson et al. 2009; Brown et al. 2010; Duriancik et al. 2008; Lee et al. 2010; Rodriguez et al. 2011; Stewart et al. 2006). The Environmental Policy Integrated Climate (EPIC) model (Williams et al. 1995), Century soil organic matter model (Parton et al. 1994), and the Soil and Water Assessment Tool (SWAT; Arnold et al. 1998) are among the tools widely used to predict water quality and $\mathrm{C}$ sequestration in agricultural systems.

The Cropland Data Layer (CDL) product (Johnson and Mueller 2010) can now be
Peter C. Beeson is a research associate at the Roger Tory Peterson Institute of Natural History, Jamestown, New York. Craig S.T. Daughtry is a research agronomist and Earle $\mathbf{R}$. Hunt Jr. is a research physical scientist at the USDA Agricultural Research Service (ARS), Hydrology and Remote Sensing Laboratory, Beltsville, Maryland. Bakyht Akhmedov is retired and formerly with Science Systems and Applications, Inc., Lanham, Maryland. Ali M. Sadeghi is a soil scientist for the USDA ARS, Hydrology and Remote Sensing Laboratory, Beltsville, Maryland. Douglas L. Karlen and Mark D. Tomer are soil scientists at the USDA ARS, National Laboratory for Agriculture and the Environment, Ames, lowa. 
et al. 2009). Crop residues may be brighter or darker than the soil depending on residue type and age, soil type, and moisture content (Nagler et al. 2000). Numerous studies have shown the potential for making multispectral estimates of tillage intensity and crop residue cover (Bricklemyer et al. 2007; Gowda et al. 2008; Hache et al. 2005; Sullivan et al. 2006; Thoma et al. 2004). Spectral indices and supervised classifications are two primary methods used for these assessments.

Several robust crop residue indices are based on detecting absorption by cellulose near 2,100 nm (Daughtry et al. 2005; Nagler et al. 2000; Serbin et al. 2009). These hyperspectral indices are linearly related to crop residue cover and are largely independent of soil type. Unfortunately, there are only a few hyperspectral satellite sensors and their areal and temporal coverage is very limited.

Currently, several satellites with broadband multispectral sensors are orbiting the Earth and can provide frequent, wide area coverage of agricultural lands. Various methods of classifying these multispectral data have been developed to identify agricultural management practices and soil properties (Bricklemyer et al. 2006, 2007; van Deventer et al. 1997). Other methods include linear logistic models (Gowda et al. 2008) and clustering and principal component analysis protocols to discriminate tillage practices and nutrient sources (Hache et al. 2007). Minimum values of the Normalized Difference Tillage Index NDTI (minNDTI) extracted from a time series of Landsat images spanning the interval from soil preparation through early crop growth reliably tracked changes in tillage intensity over agricultural regions (Zheng et al. 2012, 2013). However, the 16 day revisit cycle of Landsat (or 8 day revisit with two Landsat) and clouds have severely limited the minNDTI approach.

Pacheco et al. (2006) showed that spectral residue indices, such as Normalized Difference Index (NDI) and Modified Soil Adjusted Crop Residue Index (MSACRI), did not provide better results than supervised classification techniques like Spectral Mixing Analysis (SMA) and Spectral Angle Mapping (SAM). However, these statistical analyses are not robust and are often affected by soil type, crop residue type, and soil and residue moisture contents when the image (or scene) is collected. The result is that supervised classification methods using broad band multispectral data can often discrimi- nate among a few classes of crop residue cover, but require ground-truth (referred to as end-member data) to identify representative areas in the image that belong to each residue cover class.

The SAM technique treats reflectance spectra as vectors and separates classes based on the angle between known and unknown vectors (Kruse et al. 1993). Because the vectors are normalized, SAM is relatively insensitive to changes in irradiance and albedo, which is beneficial in terrain with rolling hills or prairie potholes. Both South et al. (2004) and Pacheco et al. (2006) showed that SAM classifications were better than multispectral indices for distinguishing between broad tillage intensity classes.

Our objective was to assess crop residue cover and soil tillage intensity using multispectral images from several diverse satellites. We tested our hypothesis by classifying multispectral imagery into two classes for high and low residue cover acquired over a watershed in central Iowa during a three year period. Identification of the satellite sensor with the best classification accuracy could provide the requirements for efficient remote sensing of tillage intensity.

\section{Methods and Materials}

Study Site. This evaluation was conducted within the South Fork watershed of the Iowa River located in central Iowa with the center coordinates of $42^{\circ} 25^{\prime} \mathrm{N}, 93^{\circ} 55^{\prime} \mathrm{W}$ (figure 1). The majority of the South Fork watershed consists of highly productive Clarion-Nicollet-Webster soils-a sequence of moderately well drained Typic Hapludolls, somewhat poorly drained Aquic Hapludolls, and poorly drained Typic Endoaquolls (NCSS 1985; Soil Survey Staff 2010). Prairie potholes are common and typically contain very poorly drained Okoboji silty clay loam soils (Cumulic Vertic Endoaquolls). Subsurface tile lines drain many of the hydric soils that occupy approximately $55 \%$ of the watershed (Tomer and James 2004).

Corn (Zea mays L.) and soybean (Glycine $\max$ [L.] Merr.) are grown on more than $85 \%$ of the land area. Both crops are typically planted from mid-April through late May and are harvested in late September through the end of October. Soil preparation prior to planting generally includes fall tillage with some type of chisel plow plus additional spring tillage with a field cultivator just before planting. Alternative tillage practices used by some producers include ridge tillage, strip tillage, and no-tillage.

Calibration and Validation Data Acquisition. In order to provide calibration and validation data over the South Fork watershed in a timely manner, we employed a stratified sampling design. Roadside survey methods were used to visually assess crop residue cover in many fields throughout the watershed, and the line-point transect method was used to directly measure crop residue cover in a few selected fields. Scheduling of transect and roadside surveys was coordinated using Crop Condition and Progress reports (USDA NASS 2012) to determine when planting was essentially completed, but before significant plant growth had begun (figure 2).

Roadside surveys were made by driving a predetermined route through the watershed, stopping every 1.6 to $3.2 \mathrm{~km}$ (1 to 2 $\mathrm{mi})$ and visually estimating the amount of residue cover in the fields on both sides of the road.Vertical and oblique images (figure 3) acquired from fields where crop residue cover was measured with line-point transect were used as references to ensure consistency between days and observers. For this study, fields with $<30 \%$ residue cover were classified as Low Residue while fields with $\geq 30 \%$ residue cover were classified as High Residue. Locations and observations were entered directly into a polygon coverage using ArcMap (ESRI, Redlands, California) with the GPS extension. For consistency, the previous crop was determined using the CDL product (Johnson and Mueller 2010). Residue cover and tillage intensity were assessed in more than 200 fields over a two to three day period using this survey method.

For the line-point transect method, two random locations that were $>100 \mathrm{~m}(>328.1$ ft) from field edges, $>100 \mathrm{~m}$ apart, and relatively homogeneous (i.e., representative of a large portion of the field) were selected for each field. At each location, two $15.2 \mathrm{~m}$ (49.8 ft) lines with 100 evenly spaced markers were stretched diagonally across the rows and the markers intersecting crop residue (greater than $3 \mathrm{~mm}$ [0.12 in]) were counted (Morrison et al. 1993). Vertical and oblique photographs were taken to document tillage and crop conditions for each location. A GPS receiver with wide area augmentation (Etrex Vista, Garmin International, Olathe, Kansas) recorded the center position of each transect pair. Fields with both corn and soybean 


\section{Figure 1}

Location of the South Fork of the lowa River watershed with overlays of the scenes for Landsat-5 Thematic Mapper (TM), Système Pour l'Observation de la Terre (SPOT) High Resolution Geometrical (HRG), Indian ResourceSat (IRS-P6) Advanced Wide Field Sensor (AWiFS), and Deimos-1. Black points are Line-Point transect sites and gray points indicate fields observed by roadside surveys (top).
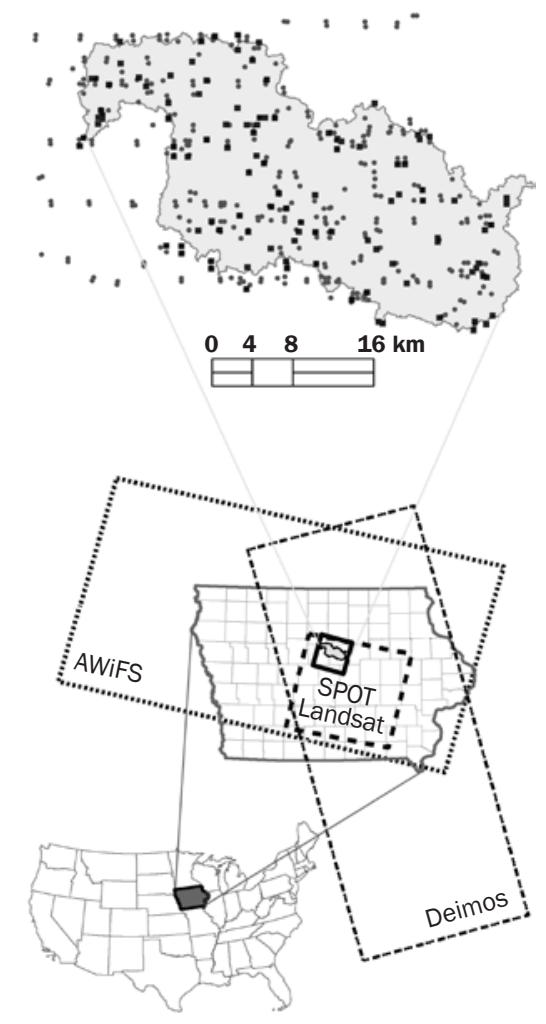

\section{Figure 2}

Timing of satellite acquisitions (vertical dotted lines, images used for classification found inside open bar), field observations (shaded bar), and crop planting progress for corn and soybean based on NASS Weekly Crop Progress and Condition reports in (a) 2009, (b) 2010, and (c) 2011.

(a)

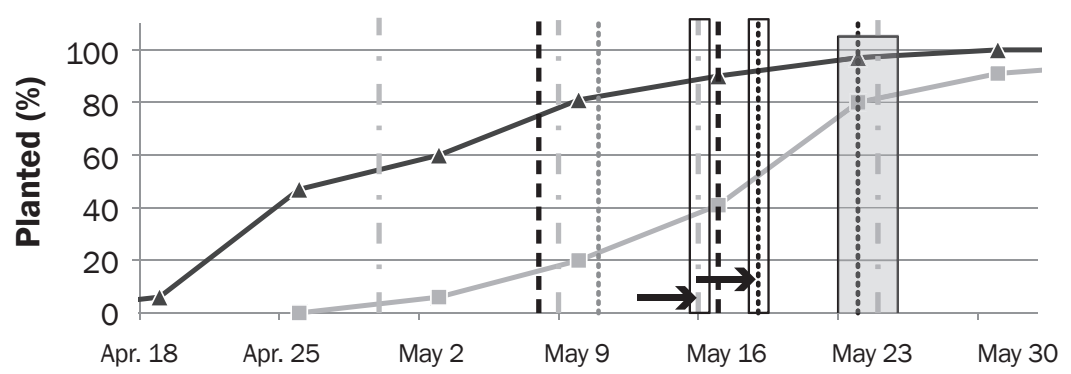

(b)

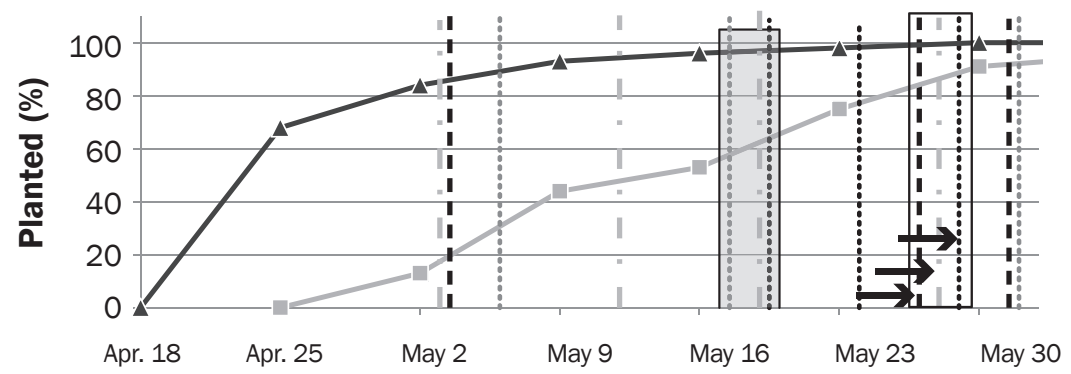

(c)

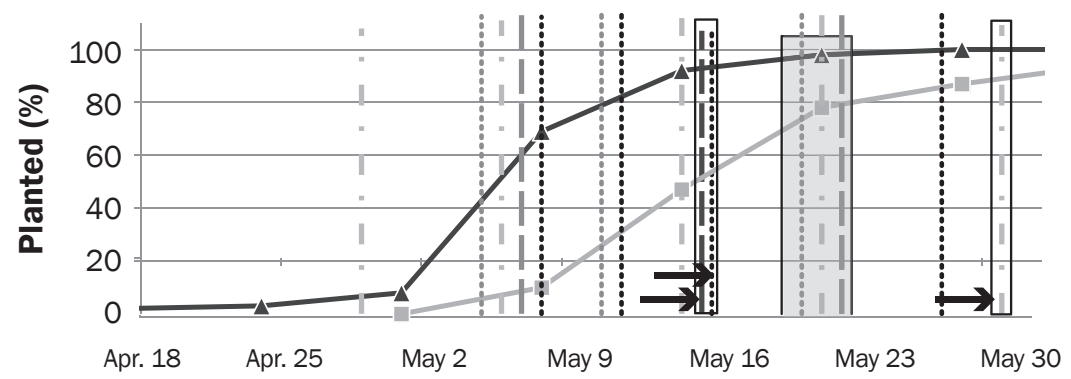

Legend

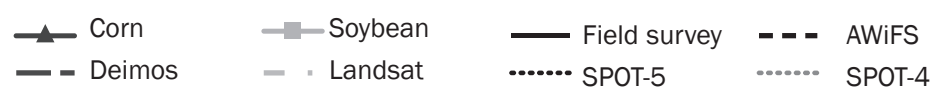

residue were assigned according to the crop grown during the previous year.

Image Acquisition and Analysis. Multispectral images from Landsat-5 Thematic Mapper (TM), Système Pour l'Observation de la Terre (SPOT) High Resolution Geometrical (HRG), Indian ResourceSat (IRS-P6) Advanced Wide Field Sensor (AWiFS), and Deimos-1 satellites were acquired to increase the probability of obtaining a cloud-free image shortly after planting. The five satellites provided different numbers of spectral bands as well as different spatial and temporal coverage of the South Fork watershed (figure 1 and table 1). Images were converted to surface reflectance using MODTRAN and the metadata provided with each image (Berk et al. 1999). Because SPOT is pointable, view zenith angles for SPOT-5 were $16.797^{\circ}$ in 2009 , $14.993^{\circ}$ in 2010 , and $16.522^{\circ}$ and $16.628^{\circ}$ in 2011. For SPOT-4 in 2011, the view zenith angle was $11.615^{\circ}$.

For classification and accuracy assessment, the USDA National Agricultural Statistical Service (NASS) CDL (Johnson and Mueller 2010) from the previous year was used to identify corn and soybean fields and to mask out other land cover types. Roadside survey and line-point transect data, collected within ten days of a satellite overpass (figure 2), were used to select fields for the reference (end-member) spectra for each crop and to assess classification accuracy. For this study, low residue fields had $<30 \%$ crop residue cover and high residue had $\geq 30 \%$ residue cover. This resulted in four classes: Corn-Low
Residue, Corn-High Residue, Soybean-Low Residue, and Soybean-High Residue.

SAM classified the multispectral images by treating the reflectance data as vectors and determining the spectral angles between each unknown spectrum and reference spectra for the four classes (Kruse et al. 1993). ENVI v. 4.8 (Exelis Visual Information Solutions, Boulder, Colorado) was used for the SAM classification. Corn and soybean classifications were merged to create the summary statistics and soil tillage intensity maps as illustrated in figure 4 .

User, producer, and overall accuracies were calculated for each image based on the roadside survey and line-point transect data that were not used as endmembers. Fields that were obviously tilled during the interval 
Figure 3

Nadir-looking and oblique-looking photographs showing $15 \%, 30 \%$, and $60 \%$ residue cover for corn (top) and soybean (bottom). Residue cover was measured using line-point transects.
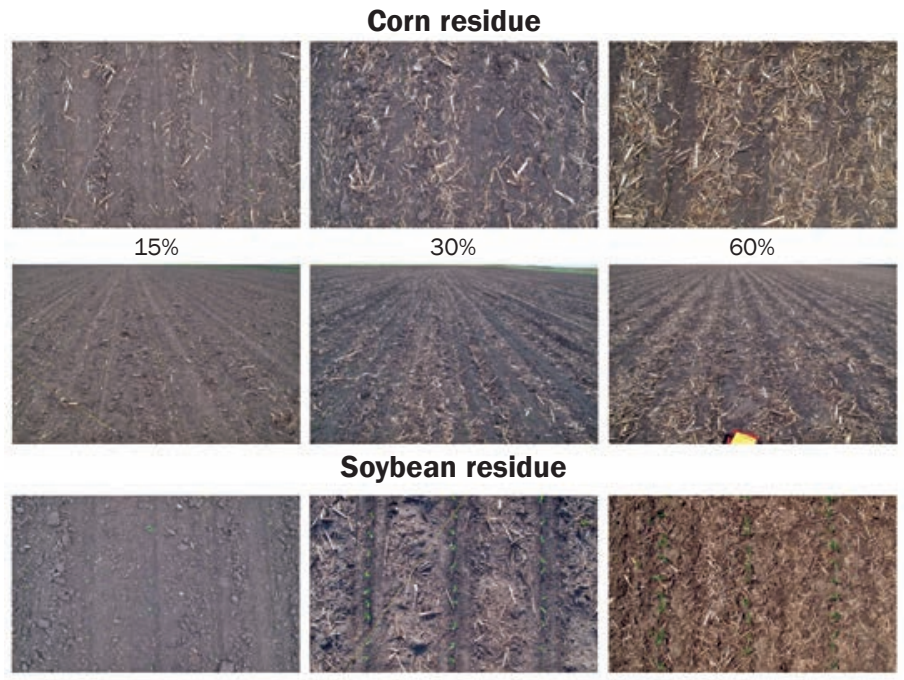

$15 \%$

$30 \%$
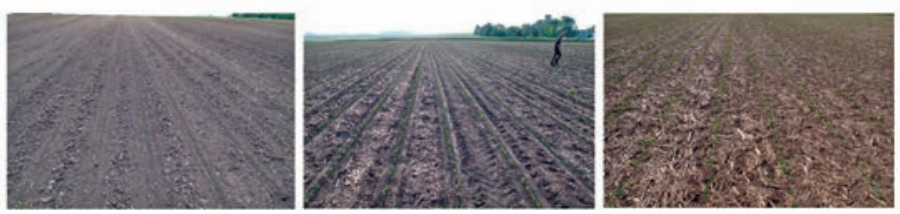

Table 1

Spectral, spatial, and temporal characteristics of the satellite sensors.

\begin{tabular}{|c|c|c|c|c|c|}
\hline$\underline{\text { Satellite }}$ & $\begin{array}{l}\text { Band } \\
\text { no. }\end{array}$ & $\begin{array}{l}\text { Spectral } \\
\text { bands } \\
(\mathrm{nm})\end{array}$ & $\begin{array}{l}\text { Spatial } \\
\text { resolution } \\
\text { (m) }\end{array}$ & $\begin{array}{l}\text { Swath } \\
\text { width } \\
(\mathrm{km}) \\
\end{array}$ & $\begin{array}{l}\text { Temporal } \\
\text { resolution } \\
\text { (days) } \\
\end{array}$ \\
\hline \multirow[t]{6}{*}{ Landsat-5* } & 1 & 450 to 520 & 30 & 185 & 16 \\
\hline & 2 & 520 to 600 & 30 & & \\
\hline & 3 & 630 to 690 & 30 & & \\
\hline & 4 & 760 to 900 & 30 & & \\
\hline & 5 & 1,550 to 1,750 & 30 & & \\
\hline & 7 & 2,080 to 2,350 & 30 & & \\
\hline \multirow[t]{5}{*}{ SPOT-5† } & 1 & 500 to 590 & 10 & 60 & 26 at nadir \\
\hline & & & & & 2 to 3 off-nadir \\
\hline & 2 & 610 to 680 & 10 & & \\
\hline & 3 & 780 to 890 & 10 & & \\
\hline & 4 & 1,580 to 1,750 & 20 & & \\
\hline \multirow[t]{4}{*}{ AWiFS } & 1 & 520 to 590 & 56 & 740 & 5 \\
\hline & 2 & 620 to 680 & 56 & & \\
\hline & 3 & 770 to 860 & 56 & & \\
\hline & 4 & 1,550 to 1,700 & 56 & & \\
\hline \multirow[t]{3}{*}{ Deimos-1 } & 1 & 520 to 600 & 22 & 600 & 2 to 3 \\
\hline & 2 & 630 to 690 & 22 & & \\
\hline & 3 & 770 to 900 & 22 & & \\
\hline
\end{tabular}

*Thermal band was not used.

†Panchromatic band was not used. Spatial resolution of SPOT-4 is $20 \mathrm{~m}$ for multispectral bands. $\ddagger$ Pointing capability facilitates rapid revisits, but is not designed for global coverage. between when the crop residue cover data were collected and when the satellite images were acquired were omitted from the accuracy assessments. Classification accuracy was assessed using the Kappa statistic, which is based on the difference between the actual agreement in the error matrix and the chance agreement (Congalton and Green 2009). Values of $Z<1.96$ indicated that two independent error matrices were not significantly different at $p=0.95$ and that the two matrices could be merged.

\section{Results and Discussion}

Field Data Analysis. Crop residue cover was measured by both line-point transect and roadside survey methods for 118 corn and 68 soybean fields. Generally, the roadside survey overestimated crop residue cover for fields with $<30 \%$ residue cover and underestimated cover for fields with $\geq 30 \%$ residue cover. Agreement between the two methods was $77 \%$ for corn and $69 \%$ for soybean. Differences in accuracy for corn and soybean were not significant $(Z$ value $=1.42)$, so the crops were combined (table 2). The overall accuracy of merged data was $74 \%$ (K-hat $=$ 0.49 , significant $Z$ value $=7.56$ with $p>$ $0.95)$ with user and producer accuracies only varying between $71 \%$ and $78 \%$.

Three major differences in the two methods that may account for these variations include: (1) observation angle (variable oblique angle from the roadside versus consistent vertical view over the line-point transect); (2) the part of the field available for observation (depending on the view from the road, the edge might only be observed versus always walking far enough into the field interior to be representative of the field); and (3) row direction (residue cover appeared greater when viewed across the rows instead of along the rows). These findings were consistent with those of Thoma et al. (2004).

Image Analysis and Comparisons. Over the three years, 37 satellite images of the watershed were acquired during the 10 days before and after the field campaigns when most of the fields in the watershed were planted (figure 2). Although none of the images acquired during the field campaigns were cloud-free, there were eight images that were suitable for analysis. The difficulties with obtaining cloud-free imagery were overcome by (1) requesting images from multiple sensors, (2) bracketing image 


\section{Figure 4}

General flow chart for classifying corn and soybean residue using spectral angle mapper (SAM).

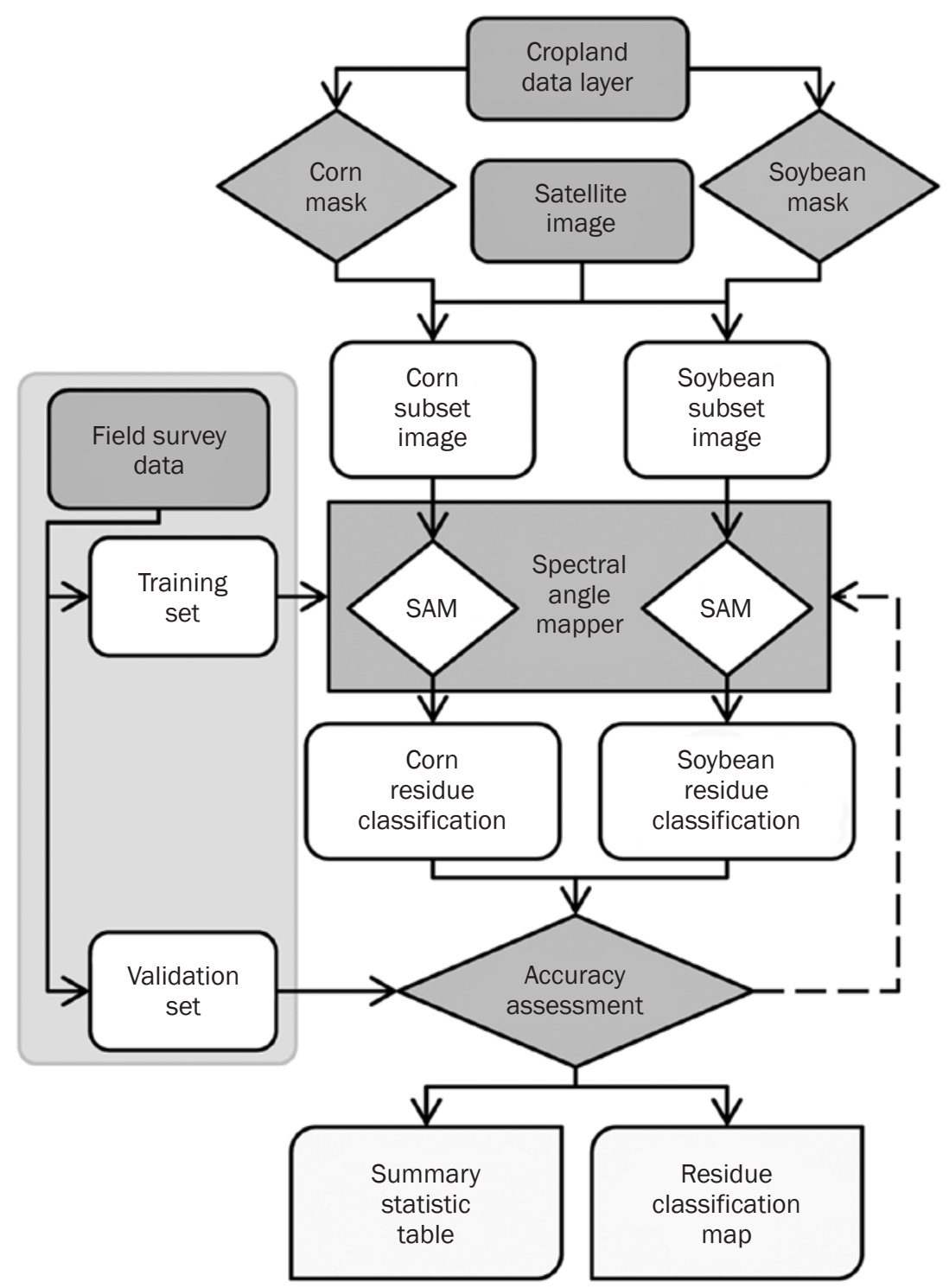

Table 2

Comparison of line-point transect and roadside survey methods for determining crop residue cover with corn and soybean data combined for two classes: Low Residue ( $0 \%$ to $30 \%)$ and High Residue (30\% to $100 \%$ ).

\begin{tabular}{|c|c|c|c|c|c|c|}
\hline & & \multicolumn{3}{|c|}{ Line-point transect } & \multicolumn{2}{|c|}{$\begin{array}{l}\text { Accuracy of } \\
\text { classification }\end{array}$} \\
\hline & & $\begin{array}{l}\text { No. of low } \\
\text { residue } \\
\text { fields }\end{array}$ & $\begin{array}{l}\text { No. of high } \\
\text { residue } \\
\text { fields } \\
\end{array}$ & $\begin{array}{l}\text { Total no. } \\
\text { of fields }\end{array}$ & $\begin{array}{l}\text { User } \\
\text { (\%) }\end{array}$ & $\begin{array}{l}\text { Overall } \\
(\%)\end{array}$ \\
\hline \multirow{3}{*}{$\begin{array}{l}\text { Roadside } \\
\text { survey }\end{array}$} & No. of low residue fields & 70 & 28 & 98 & 71 & \\
\hline & No. of high residue fields & 20 & 68 & 88 & 77 & \\
\hline & Total no. of fields & 90 & 96 & 186 & & \\
\hline \multirow{2}{*}{$\begin{array}{l}\text { Accuracy of } \\
\text { classification }\end{array}$} & Producer (\%) & 78 & 71 & & & \\
\hline & Overall (\%) & & & & & 74 \\
\hline
\end{tabular}

Note: K-hat $=0.49$. requests before and after the field campaigns, and (3) using historic and current-year crop progress reports to plan the field campaigns.

The spectral reflectance of the training fields (endmembers) varied from year-toyear and demonstrated that annual ground truth (surface reference) data are essential (figure 5). When selecting training fields, care was taken to not choose fields that had emerged crops or were obviously tilled after the observation. The spectral angles between high and low residue for each crop type, sensor, and year are presented in figure 6 . For Landsat, SPOT, and AWiFS, the spectral angles between corn fields with low residue and high residue were $>0.06$ radians $\left(>3.44^{\circ}\right)$, which indicated good separability. However, there were only three occurrences in which soybean fields had spectral angles $>0.06$ radians (figure 6 ). With only three spectral bands, Deimos could not consistently distinguish between the two tillage classes. The poor separation between the two tillage classes in soybean, and good separation in corn, may be related to corn residue having greater mass for a given amount of cover (Daughtry et al. 2005).

Ideally, crop residue cover in each field would have been measured on the same day that the satellite image was acquired, but temporal resolution of the satellites (table 1) and clouds during the satellite overpass limited the number of suitable images. In practice, all suitable satellite images acquired within ten days of the field measurements were used (figure 2). Tillage operations during the interval between image acquisition and ground truth measurements of crop residue cover added uncertainty. Therefore, spectra for endmembers of both tillage intensity classes were evaluated carefully to avoid misclassifications.

Overall classification accuracy of residue cover for corn and soybean were not significantly different and the crops were combined (table 3). For 2009 (field surveys May 23 to 26), SPOT (May 19) and Landsat (May 16) yielded similar results with combined accuracies of $78 \%$ and $76 \%$, respectively. User and producer accuracies for SPOT and Landsat were similar and varied from $65 \%$ to $86 \%$. For 2010 (field surveys May 17 to 20), SPOT (May 29), Landsat (May 28), and AWiFS (May 27) had overall combined accuracies of $89 \%, 74 \%$, and $79 \%$, respectively, and the user and producer accuracy varied $59 \%$ to $95 \%$ (table 3). However, the combined K-hat for Landsat was 0.40, 


\section{Figure 5}

Reflectance factors of low and high residue cover endmembers obtained from Landsat- 5 Thematic Mapper images for 2009 to 2011 for (a) corn and (b) soybean. Note the significant interannual variability for reflectance. See table 1 for the spectral bands.

(a)

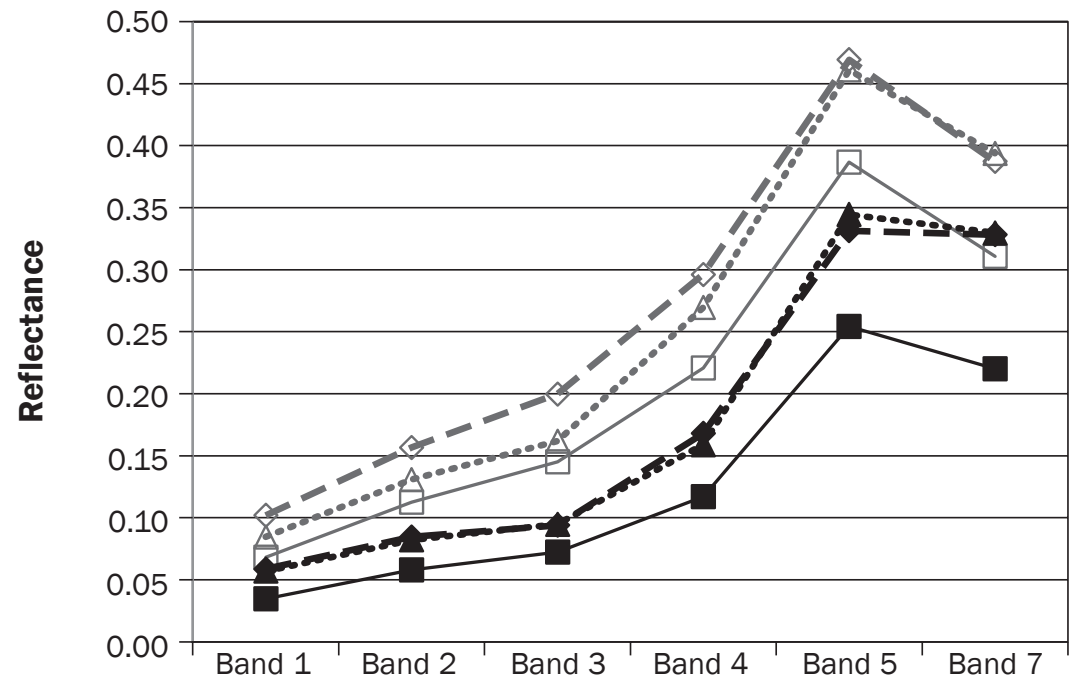

(b)

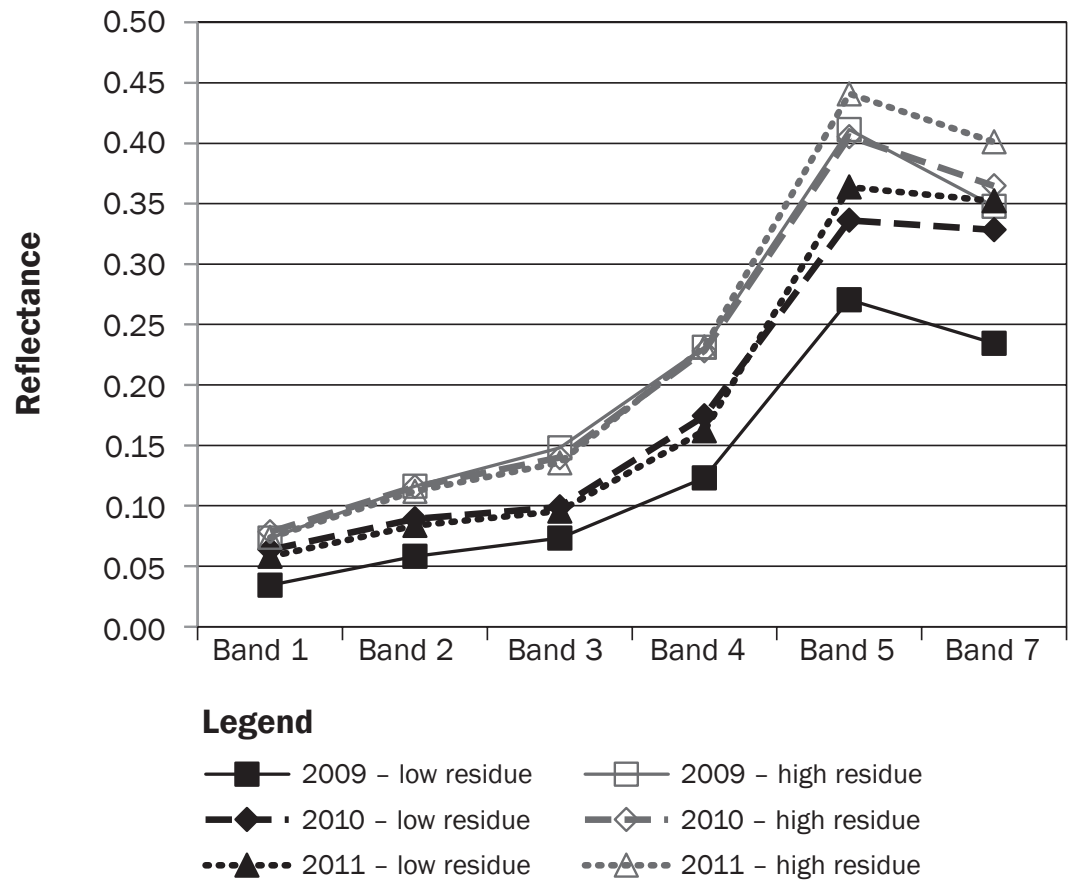

year, but the classification was more difficult because of the dearth of high residue soybean fields to use for training purposes. However, even though this group of images had the lowest endmember spectral angles, they were among the highest in overall accuracy with the exception of Landsat data. Accuracy and K-hat were related $\left(R^{2}=0.80\right.$ for corn, $R^{2}=0.56$ for soybean), as expected, but spectral angles between the endmembers were not related to accuracy $\left(R^{2}=0.06\right.$ for corn, $R^{2}=0.28$ for soybean). Spectral angles of the endmembers and $\mathrm{K}$-hat for corn were not related $\left(R^{2}=0.05\right)$, but slightly related for soybean $\left(R^{2}=0.55\right)$.

Pairwise $Z$-tests indicated no significant differences among the sensors in 2009 and 2010 (table 4), but there were significant differences in 2011 between the SPOT data and the other two sensors (table 4). The differences in 2011 did not correspond to either the sensor characteristics (table 1) or scene orientation variation for SPOT 5 and 4 mosaic, so this result may be simply spurious. The general agreement among the various sensors indicates that when clouds obscure one satellite, data from another satellite may be used with little effect on accuracy. Only SPOT and Landsat had suitable images for all three years. Pairwise $Z$-tests showed no significant yearly differences among them $(Z$ values < 1.96) (table 5).

Crop Residue in the South Fork Watershed. When the entire South Fork watershed was classified, residue cover maps were produced (figure 7) and summarized (table 6) for each sensor and year. Classifications of SPOT and Landsat images produced similar proportions for each residue class, not varying by more than $6 \%$ over the three years. Both AWiFS and Deimos overestimated high residue classes for fields with corn residue, but not for fields with soybean residue. However, with only one year of data available for those two sensors, these results were inconclusive for mapping tillage intensity over large areas.

More than half of the cropland in the South Fork watershed has slopes $<2 \%$ (figure 8 ). The distribution of tillage intensity by slope for all the cropland in the watershed showed more occurrences of Low Residue classifications on flatter areas, typically in the headwaters, and high residue classifications on steeper landscapes, typically near the outlet. When tillage intensity was normalized for each slope class, the proportion of high residue cover increased as slope class increased 


\section{Figure 6}

Spectral angles between low and high residue cover endmembers. A threshold angle of 0.06 radians may be required for accurate spectral angle mapper (SAM) classifications.

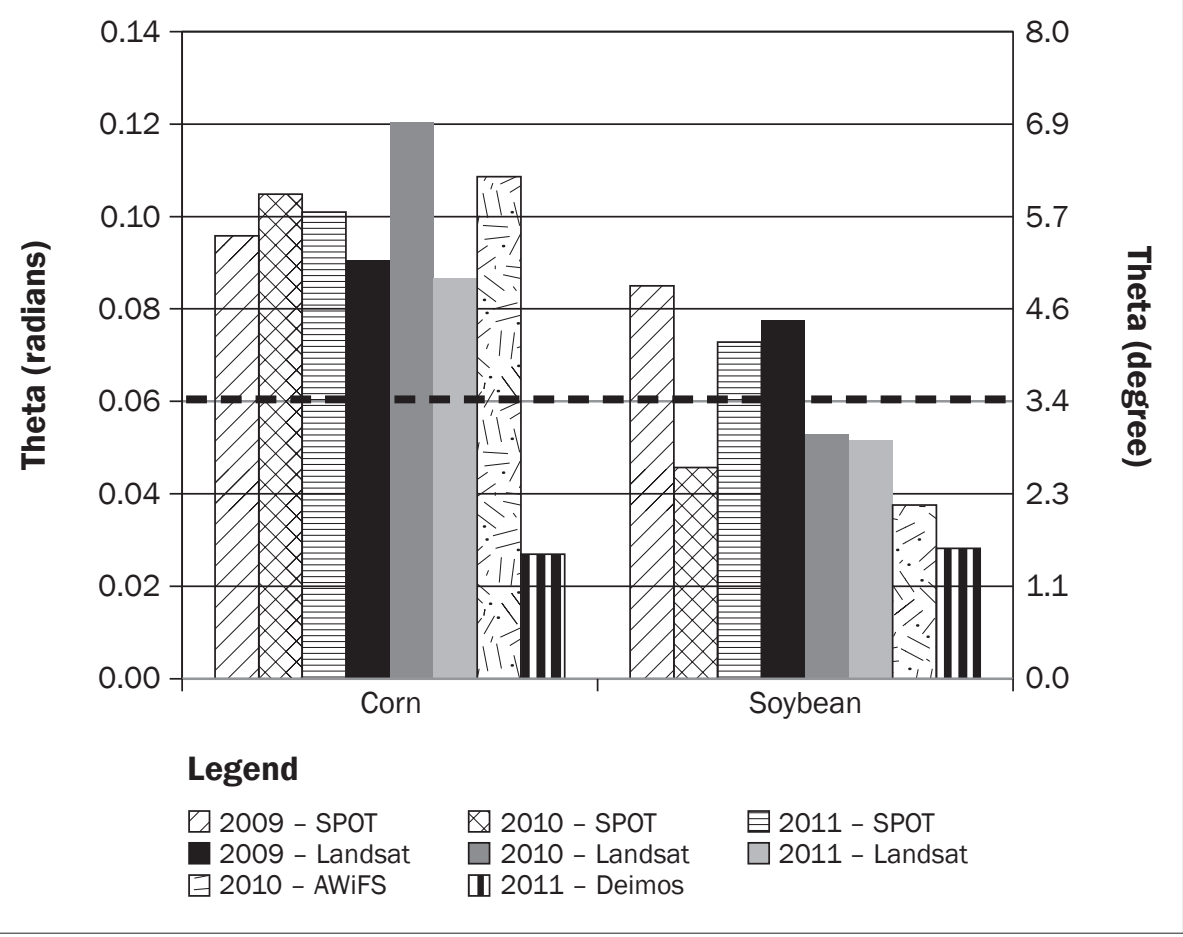

(figure 9). For example, in 2011 occurrences of high residue cover were evident on $20 \%$ to $30 \%$ of cropland with slopes $<2 \%$ and nearly $85 \%$ of cropland with slopes $>5 \%$. Nevertheless, almost $15 \%$ of cropland with slopes $>5 \%$ had little crop residue cover and may need additional conservation practices to minimize soil erosion. Currently, low soil disturbance practices are dominant in fields with slopes over $2.5 \%$ (figure 9), but site visits are crucial to verify classification results.

In this study, $43 \%$ of the watershed cropland had high residue, which is less than the $65 \%$ low soil disturbance reported by Tomer et al. (2008) for 2005. This discrepancy is probably due to the timing of data collection. Tomer et al. (2008) collected their data over a three week period between April 27 and May 17, 2005. By May 15, 2005, 96\% of the corn acreage was planted, but only $45 \%$ of the soybean acreage was planted (USDA NASS 2012). Corn and soybean are often grown rotation, thus soybean would typically have been planted into previous corn fields that are likely to have high corn residue cover

\section{Table 3}

Summary statistics and the number of field used as endmembers and accuracy assessment for the eight classified images for corn, soybean, and combined corn-soybean residue classes.

\begin{tabular}{|c|c|c|c|c|c|c|c|c|}
\hline \multirow{2}{*}{$\begin{array}{l}\text { Field survey } \\
\text { Imagery date }\end{array}$} & \multicolumn{2}{|c|}{$\begin{array}{l}2009 \\
\text { May } 23 \text { to } 26\end{array}$} & \multicolumn{3}{|c|}{$\begin{array}{l}2010 \\
\text { May } 17 \text { to } 20\end{array}$} & \multicolumn{3}{|c|}{$\begin{array}{l}2011 \\
\text { May } 20 \text { to } 23\end{array}$} \\
\hline & $\begin{array}{l}\text { SPOT-5 } \\
\text { May } 19 \\
\end{array}$ & $\begin{array}{l}\text { Landsat } \\
\text { May } 16\end{array}$ & $\begin{array}{l}\text { SPOT-5 } \\
\text { May } 29 \\
\end{array}$ & $\begin{array}{l}\text { Landsat } \\
\text { May } 28 \\
\end{array}$ & $\begin{array}{l}\text { AWiFS } \\
\text { May } 27\end{array}$ & $\begin{array}{l}\text { SPOT4/5t } \\
\text { May } 16 / 17\end{array}$ & $\begin{array}{l}\text { Landsat } \\
\text { May } 31\end{array}$ & $\begin{array}{l}\text { Deimos } \\
\text { May } 16 \\
\end{array}$ \\
\hline \multicolumn{9}{|l|}{ Corn } \\
\hline Overall (\%) & 80 & 74 & 87 & 73 & 79 & $79 / 76$ & 75 & 70 \\
\hline K-hat & 0.58 & 0.47 & 0.54 & 0.43 & 0.58 & $0.59 / 0.51$ & 0.51 & 0.28 \\
\hline \multicolumn{9}{|l|}{ Soybean } \\
\hline Overall (\%) & 69 & 86 & 92 & 77 & 81 & $81 / 87$ & 64 & 61 \\
\hline K-hat & 0.27 & 0.68 & 0.67 & 0.34 & 0.43 & $0.48 / 0.31$ & 0.31 & 0.21 \\
\hline Endmembers & 4 & 5 & 4 & 4 & 4 & $8 / 8$ & 10 & 7 \\
\hline Assessment & 16 & 22 & 27 & 31 & 26 & $64 / 106$ & 101 & 125 \\
\hline \multicolumn{9}{|l|}{ Combined } \\
\hline Low residue (\%) & 81 & 75 & 91 & 77 & 81 & 80 & 77 & 83 \\
\hline High residue (\%) & 72 & 77 & 72 & 68 & 76 & 84 & 64 & 58 \\
\hline \multicolumn{9}{|l|}{ Producer accuracy } \\
\hline Low residue (\%) & 86 & 84 & 95 & 88 & 85 & 92 & 70 & 49 \\
\hline High residue (\%) & 65 & 66 & 59 & 50 & 70 & 65 & 72 & 88 \\
\hline
\end{tabular}

*For $p=0.95, Z$-values $<1.96$ were not significance, so classes were combined.

†SPOT-4 and 5 classified separately and classification merged for combined result. 
Table 4

$Z$-tests between sensors for three years. The level of significance was $p=0.95$, so $Z$-values < 1.96 were not significant. Corn and soybean classes were combined.

\begin{tabular}{llll}
\hline Sensor & $\mathbf{2 0 0 9}$ & $\mathbf{2 0 1 0}$ & $\mathbf{2 0 1 1}$ \\
\hline SPOT/Landsat & 0.14 & 1.29 & 2.20 \\
SPOT/AWiFS & - & 0.14 & - \\
Landsat/AWiFS & - & 1.23 & - \\
SPOT/Deimos & - & - & 2.97 \\
Landsat/Deimos & - & - & 0.76
\end{tabular}

\section{Table 5}

Pairwise comparisons between years for Landsat and SPOT data. The level of significance was $p=0.95$, so Z-values $<1.96$ were not significant.

\begin{tabular}{|c|c|c|c|c|c|c|}
\hline \multirow[b]{2}{*}{ Crop } & \multicolumn{3}{|l|}{ SPOT } & \multicolumn{3}{|l|}{ LANDSAT } \\
\hline & $2009 / 2010$ & $2010 / 2011$ & $2009 / 2011$ & $2009 / 2010$ & $2010 / 2011$ & $2009 / 2011$ \\
\hline Corn & 0.01 & 0.01 & 0.06 & 0.01 & 0.02 & 0.32 \\
\hline Combined & 0.50 & 0.05 & 0.73 & 0.84 & 0.08 & 1.01 \\
\hline
\end{tabular}

\section{Table 6}

Summarized soil tillage intensity class percentages over the South Fork watershed.

\begin{tabular}{|c|c|c|c|c|c|c|c|c|}
\hline \multirow[b]{2}{*}{ Tillage intensity } & \multicolumn{2}{|l|}{2009} & \multicolumn{3}{|l|}{2010} & \multicolumn{3}{|l|}{2011} \\
\hline & SPOT & Landsat & SPOT & Landsat & AWiFS & SPOT & Landsat & Deimos \\
\hline \multicolumn{9}{|l|}{ Corn } \\
\hline High Residue (\%) & 32 & 34 & 26 & 21 & 33 & 28 & 28 & 48 \\
\hline \multicolumn{9}{|l|}{ Soybean } \\
\hline Low Residue (\%) & 16 & 21 & 13 & 14 & 14 & 20 & 15 & 17 \\
\hline \multicolumn{9}{|l|}{ Overall } \\
\hline Low Residue (\%) & 52 & 57 & 59 & 65 & 52 & 61 & 56 & 38 \\
\hline High Residue (\%) & 48 & 43 & 41 & 36 & 48 & 39 & 44 & 62 \\
\hline
\end{tabular}

and appear to be under conservation tillage practices. Tillage operations prior to planting often reduce crop residue cover significantly and may not have been captured due to timing of the survey (Tomer et al. 2008), and thus resulted in higher estimates of conservation tillage. Furthermore, with the increased demand for corn grain to produce ethanol in recent years, there is more continuous corn. Therefore, unless the stover is being harvested, the amount of residue remaining in the field may require more tillage to manage surface cover and aid in its decomposition (Coulter and Nafzinger 2008).

\section{Summary and Conclusions}

The line-point transect method can quantitatively assess crop residue cover for a few fields in a timely manner. On the other hand, roadside surveys are somewhat subjective but can qualitatively assess many fields in a timely manner. Remote sensing offers a potential method to observe many fields and capture the spatial variability of tillage practices across agricultural landscapes. Tillage intensity of all corn and soybean fields in a watershed in central Iowa was successfully evaluated with SPOT, Landsat, AWiFS, and Deimos images. Timing of the satellite images relative to crop planting progress is crucial-ideally shortly after planting, but before significant crop growth. If clouds obscure one satellite, our data indicates another satellite could be substituted, usually with little effect on accuracy. Overall, remote sensing images were well suited for classifying tillage intensity based on crop residue cover over large areas and targeting where additional conservation efforts may be needed.
For regions such as the South Fork watershed, where corn and soybean are the dominant crops and soil preparation and planting typically occur rapidly over few weeks, a single satellite image may be sufficient to classify soil tillage intensity. However, for watersheds with a diverse mixture of crops, double cropping, and/or soil preparation and planting that occurs over an extended period, multitemporal sequences of images are required to identify when tillage occurred and then to estimate crop residue cover and soil tillage intensity for each field before the growing crop obscures the soil and crop residue (Zheng et al. 2013)

Spatial and temporal resolution trade-offs have resulted in satellite sensors that are suboptimal for these agricultural applications. One method to obtain both high spatial and temporal resolution is to combine remote 


\section{Figure 7}

Soil tillage intensity maps for the South Fork watershed by year ([a, d] 2009, [b, e, g] 2010, and [c, f, h] 2011) and sensor ([a, b, c] SPOT, [d, e, f] LANDSAT, [g] AWiFS, and [h] Deimos). Other land cover types and clouds were masked out (white).

(a)

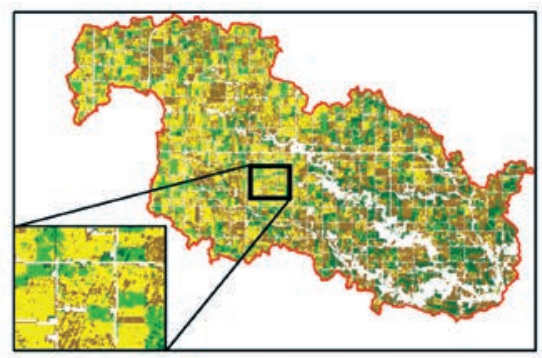

(d)

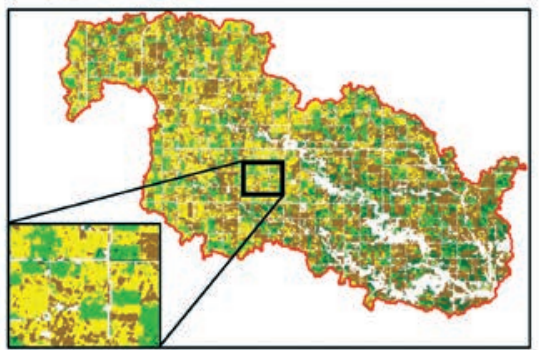

Legend

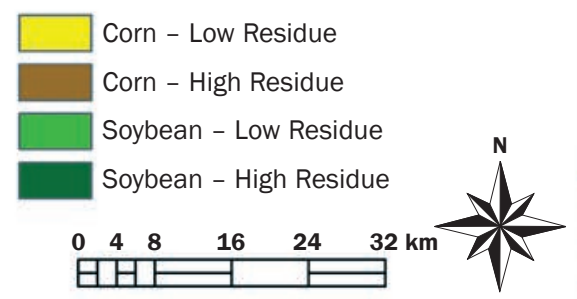

(b)

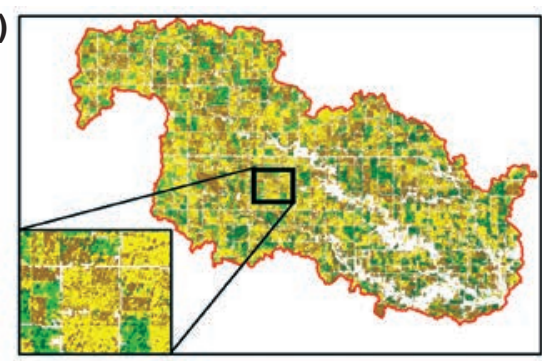

(e)

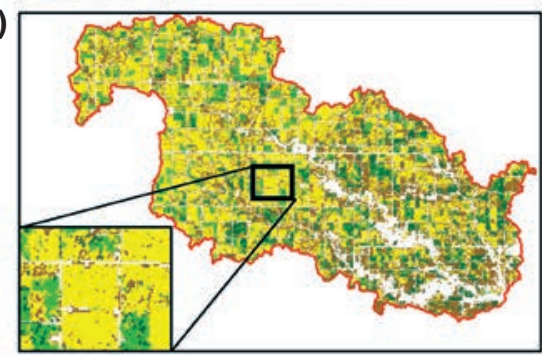

(g)

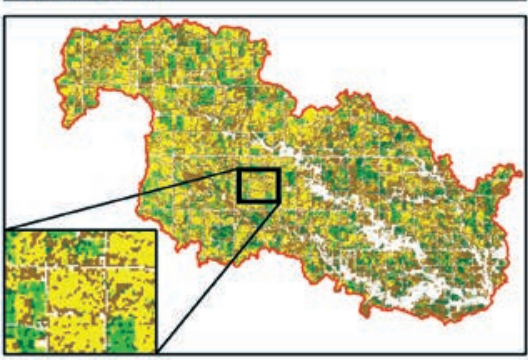

(c)

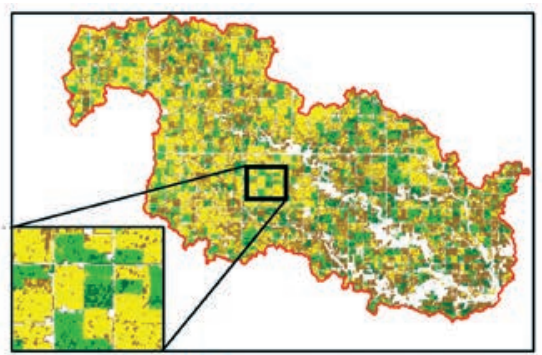

(f)

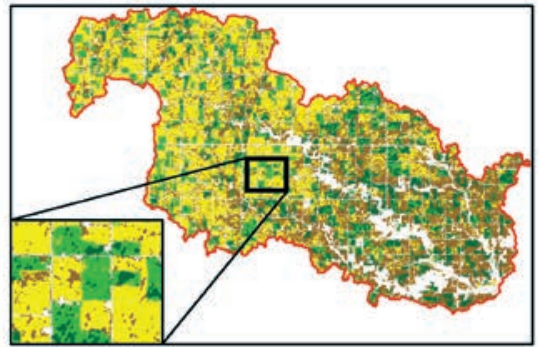

(h)

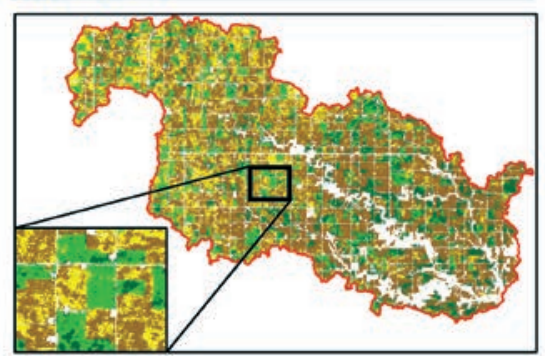

sensing data from multiple sources. Data fusion approaches combine the spatial resolution (30 $\mathrm{m}[98.4 \mathrm{ft}], 16$ day repeat) of Landsat with the temporal frequency (250 and 500 $\mathrm{m}$ [820.2 and 1,640 ft], near daily repeat) of MODIS (Gao et al. 2010, 2015). The fused Landsat-MODIS images capture temporal variations possible with MODIS and show spatial details that can only be observed at Landsat spatial resolution. An alternative approach is to combine data from multiple Landsat-like sources. The recently launched Landsat- 8 and Sentinel-2A satellites (Drusch et al. 2012) have multispectral sensors with spectral and spatial resolutions comparable to Landsat-5. The combined data from these two satellite series should provide improved temporal ( $<5$ day) coverage (Wulder and Coops 2014) for many agricultural monitoring applications including crop residue cover and soil tillage intensity assessments.

\section{Disclaimer}

USDA prohibits discrimination in all its programs and activities on the basis of race, color, national origin, age, disability, and where applicable, sex, marital status, familial status, parental status, religion, sexual orientation, genetic information, political beliefs, reprisal, or because all or part of an individual's income is derived from any public assistance program. The USDA is an equal opportunity provider and employer.

\section{References}

Abrahamson, D.A., H.J. Causarano, J.R. Williams, M.L. Norfleet, and A.J. Franzluebbers. 2009. Predicting soil organic carbon sequestration in the southeastern United States with EPIC and the soil conditioning index. Journal of Soil and Water Conservation 64(2):134-144 doi:10.2489/jswc.64.2.134.

Arnold, J.G., R. Srinivasan, R.S. Muttiah, and J.R. Williams. 1998. Large-area hydrologic modeling and assessment: Part I. Model development. Journal of the American Water Resources Association 34(1):73-89.

Beeson, P.C., P.C. Doraiswamy, A.M. Sadeghi, M. Di Luzio, M.D. Tomer, J.G. Arnold, and C.S.T. Daughtry. 2011 Treatments of precipitation inputs to SWAT models. Transactions of the American Society of Agricultural and Biological Engineers 54(6):2011-2020.

Berk, A., G.P. Anderson, P.K. Acharya, J.H. Chetwynd, L.S. Bernstein, E.P. Shettle, M.W. Matthew, and S.M
Adler-Golden. 1999. MODTRAN4 User's Manual., Hanscom Air Force Base, Massachusetts: Air Force Research Laboratory.

Bricklemyer, R.S., R.L. Lawrence, P.R. Miller, and N. Battogtokh. 2006. Predicting tillage practices and agricultural soil disturbance in north central Montana with Landsat imagery. Agriculture Ecosystems and Environment 114:210-216.

Bricklemyer, R.S., R.L. Lawrence, P.R. Miller, and N. Battogtokh. 2007. Monitoring and verifying agricultural practices related to soil carbon sequestration with satellite imagery. Agriculture Ecosystems and Environment 118:201-210.

Brown, D.J., E.R. Hunt Jr., R.C. Izaurralde, K.H. Paustian, C.W. Rice, B.L. Schumaker, and T.O. West. 2010. Soil organic carbon change monitored over large areas. Eos Transactions American Geophysical Union 91(47):441-442

CTIC (Conservation Technology Information Center). 2009.

Cropland roadside transect survey 2009: Procedures for using the cropland roadside transect survey for obtaining tillage/crop residue data. West Lafayette, IN: Conservation Technology Information Center, Purdue University. http://www.ctic.purdue.edu. 


\section{Figure 8}

Distribution of tillage intensity as function of slope class for the South Fork watershed (black lines are low residue and gray lines are high residue).

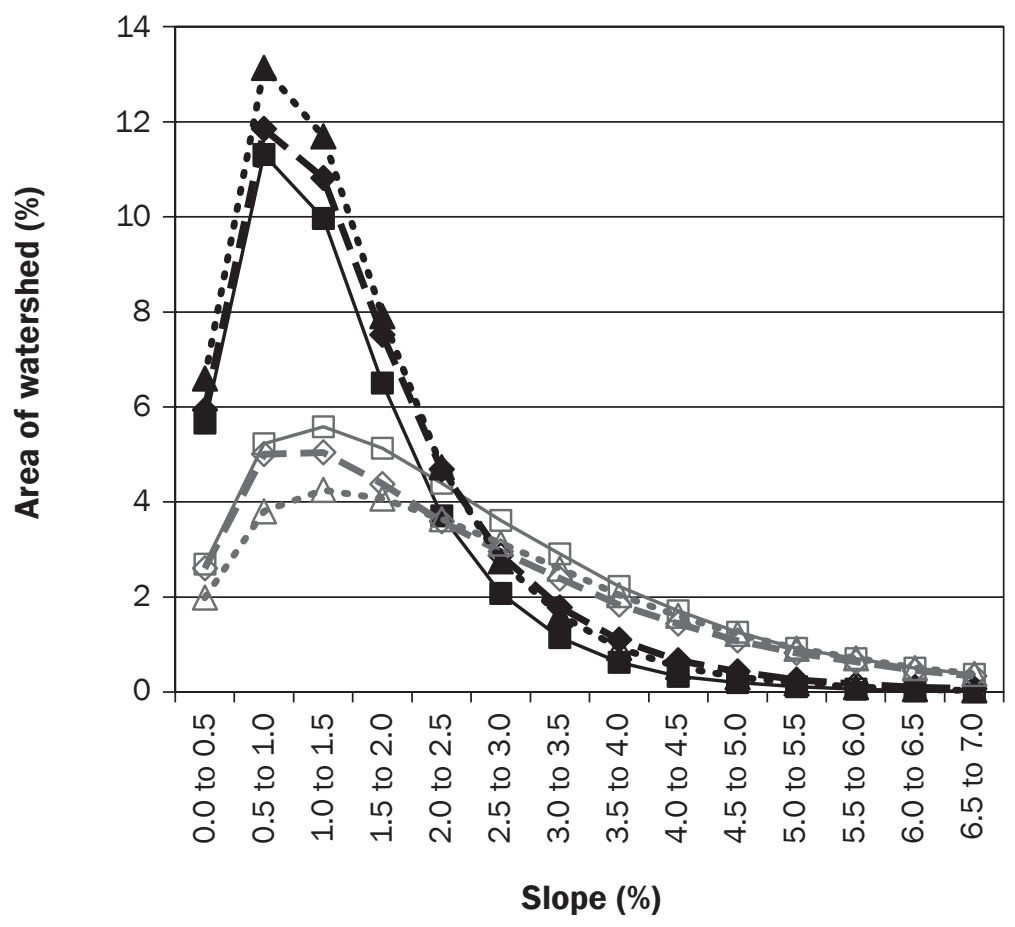

\section{Legend}

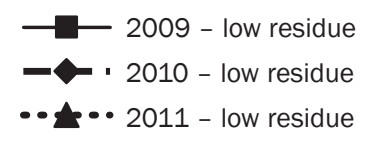

practices with airborne multispectral imagery. Agriculture, Ecosystems and Environment 111:354-366. Hache, C., S. Shibusawa, A. Sasao, T. Suhama, and B.P. Sah. 2007. Field-derived spectral characteristics to classify conventional and conservation agricultural practices. Computers and Electronics in Agriculture 57:47-61.

Hunt Jr., E.R., C.S.T. Daughtry, M.S. Kim, and A.E.P. Williams. 2007. Using canopy reflectance models and spectral angles to assess potential of remote sensing to detect invasive weeds. Journal of Applied Remote Sensing 1:013506.

Johnson, D.M., and R. Mueller. 2010. The 2009 cropland data layer. Photogrammetric Engineering and Remote Sensing 76(11):1201-1205.

Kruse, F.A., A.B. Lefkoff, J.W. Boardman, K.B. Heidebrecht, A.T. Shapiro, P.J. Barloon, and A.F.H. Goetz. 1993. The spectral image processing system (SIPS) - Interactive visualization and analysis of imaging spectrometer data. Remote Sensing of Environment 44:145-163.

Lal, R., T.M. Sobeski, T. Iivary, and J.M. Kimble. 2004. Soil degradation in the United States, Boca Raton, FL: Lewis Publishers.

Lee, T., M.E. Rister, B. Narashimhan, R. Srinivasan, D. Andrew, and M.R. Ernst. 2010. Evaluation and spatially distributed analyses of proposed cost-effective BMPs for reducing phosphorous level in Cedar Creek Reservoir, Texas. Transactions of the American Society of Agricultural and Biological Engineers 53(5):1619-1627.

Morrison, J.E., C. Huang, D.T. Lightle, and C.S.T. Daughtry. 1993. Residue cover measurement techniques. Journal of Soil Water Conservation 48(6):479-483.

Nagler, P.L., C.S.T. Daughtry, and S.N. Goward. 2000. Plant litter and soil reflectance. Remote Sensing of Environment 71:207-215.

NCSS (National Cooperative Soil Survey). 1985. Soil Survey of Hardin County Iowa. USDA Soil Conservation Service, and Iowa State University Cooperative Extension Service. Washington, DC: US Government Printing Office.

Pacheco, A., H. McNairn, and A.M. Smith. 2006. Multispectral indices and advanced classification techniques to detect percent residue cover over agricultural crops using Landsat data. In Proceeding of the Society of Photo-Optical Instrumentation Engineers (SPIE) - Conference on Remote Sensing and Modeling of Ecosystems for Sustainability III, ed.W. Gao and S.L. Ustin, Vol 6298. Bellingham, WA: Society of Photo-Optical Instrumentation Engineers.

Parton, W.J., D.S. Ojima, C.V. Cole, and D.S. Schimel. 1994. A general model for soil organic matter dynamics: Sensitivity to litter chemistry, texture, and management. In Quantitative Modeling of Soil Forming Processes, ed. R.B. Bryant and R.W. Arnold, Special Publication 39, 147-167. Madison, WI: American Society of Agronomy, 


\section{Figure 9}

Relative proportions of tillage intensity in each slope class for the South Fork watershed (black lines are low residue and gray lines are high residue).
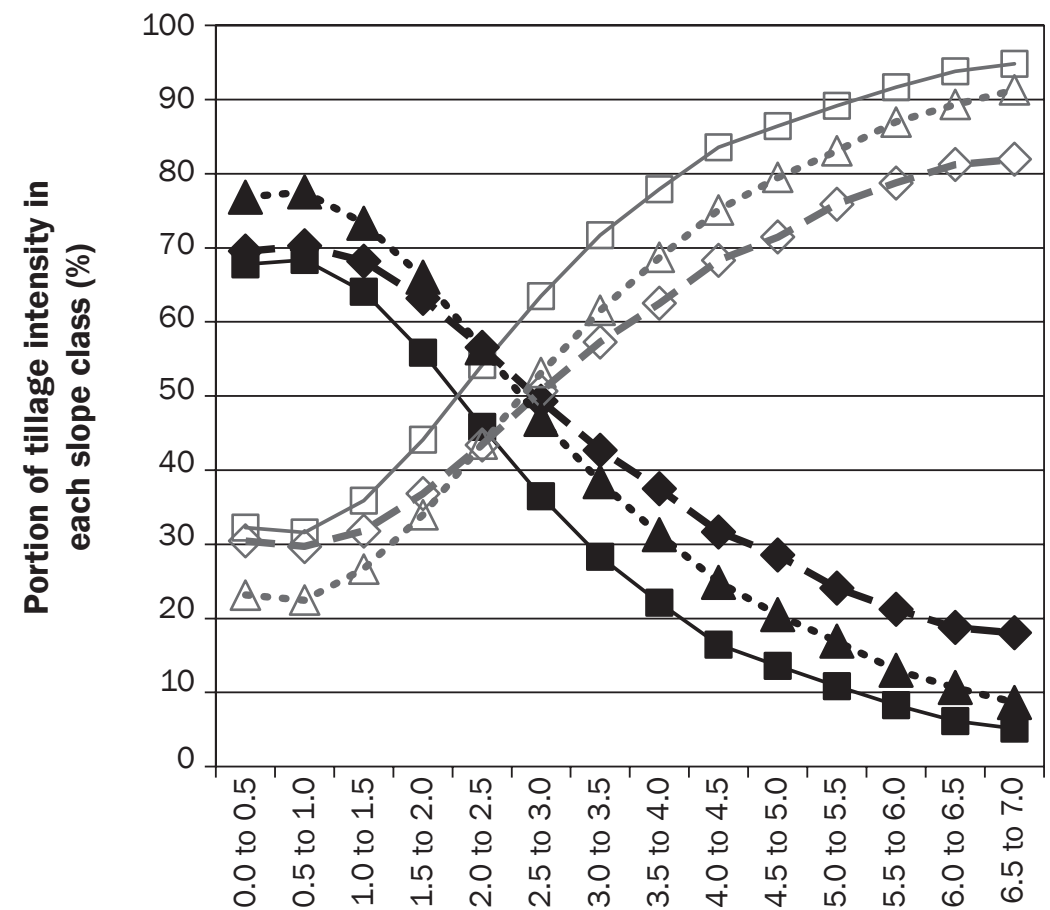

Slope class (\%)

\section{Legend}

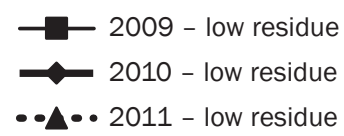

http://www.nass.usda.gov/Statistics_by_State/Iowa/ Publications/Crop_Progress_\&_Condition/index.

van Deventer, A.P., A.D. Ward, P.H. Gowda, and J.G. Lyon. 1997. Using thematic mapper data to identify contrasting soil plains and tillage practices. Photogrammetric Engineering and Remote Sensing 63(1):87-93.

Williams,J.R. 1995.The EPIC Model. In Computer Models of Watershed Hydrology, ed.V.P. Singh, 909-1000. Highlands Water Ranch, CO: Resources Publications.

Wulder, M.A., and N.C. Coops. 2014. Satellites: Make Earth observations open access. Nature 513:30-31.

Zheng, B., J.B. Campbell, and K.M. de Beurs. 2012. Remote sensing of crop residue cover using multitemporal Landsat imagery. Remote Sensing of Environment 117:177-183.

Zheng, B., J.B. Campbell, G. Serbin, and C.S.T. Daughtry. 2013. Multitemporal remote sensing of crop residue cover and tillage practices: A validation of the minNDTI strategy in the United States. Journal of Soil and Water Conservation 68(2):120-131, doi:10.2489/ jswc.68.2.120.
Crop Science Society of America, and Soil Science Society of America.

Rodriguez, H.G., J. Popp, C. Maringanti, and I. Chaubey. 2011. Selection and placement of best management practices used to reduce water quality degradation in Lincoln Lake watershed. Water Resources Research 47(1):1-13.

Serbin, G., C.S.T. Daughtry, E.R. Hunt Jr., D.J. Brown, and G.W. McCarty. 2009. Effect of soils spectral properties on remote sensing of crop residue cover. Soil Science Society of America Journal 73:1545-1558.

Soil Survey Staff. 2010. Keys to soil taxonomy, 11th Ed. Washington, DC: USDA Natural Resources Conservation Service.

South, S., J. Qi, and D.P. Lusch. 2004. Optimal classification methods for mapping agricultural tillage practices. Remote Sensing of Environment 91(1):90-97.

Stewart, G.R., C.L. Munster, D.M. Vietor, J.G. Arnold, A.M.S. McFarland, R. White, and T. Provin. 2006. Simulating water quality improvements in the Upper North Bosque River Watershed due to phosphorus export through turfgrass sod. Transactions of the
American Society of Agricultural and Biological Engineers 49(2):357-366.

Sullivan, D.G., C.C. Truman, H.H. Schomberg, D.M Endale, and T.C. Strickland. 2006. Evaluating techniques for determining tillage regime in the Southeastern Coastal Plain and Piedmont. Agronomy Journal 98(5):236-1246.

Thoma, D.P., S.C. Gupta, and M.E. Bauer. 2004 Evaluation of optical remote sensing models for crop residue cover assessment. Journal of Soil and Water Conservation 59(5):224-233.

Tomer, M.D, and D.E.James. 2004. Do soil surveys and terrain analyses identify similar priority sites for conservation? Soil Science Society of America Journal 68:1905-1915.

Tomer, M.D., T.B. Moorman, D.E. James, G. Hadish, and C.G. Rossi. 2008. Assessment of the Iowa River's South Fork watershed: Part 2. Conservation practices. Journal of Soil and Water Conservation 63(6):371-379, doi:10.2489/jswc.63.6.371.

USDA NASS (National Agricultural Statistics Service). 2012. Crop condition and progress reports. Washington, DC: USDA National Agricultural Statistics Service. 